\title{
The disposition effect in the absence of taxes
}

\author{
Chris Firth \\ EDHEC-Risk Institute, BP 3116, 06202 Nice Cedex, France \\ chrisfirth at alum.mit.edu \\ (C) Copyright 2015 \\ http://ssrn.com/abstract=2601745
}

May 13, 2015

I measure household investment decisions undertaken in a setting that is free from investment taxes. The disposition effect is unequivocally present, but any seasonal impact of tax-loss selling is absent. There is evidence that the disposition effect correlates positively with inferior risk-adjusted investment performance. Although household preferences are unknown, losses cannot be explained by tax benefits.

$\begin{array}{cc}\text { JEL classification: } & \text { Keywords: } \\ \text { D12 } & \text { Disposition effect } \\ \text { G02 } & \text { Tax distortions } \\ \text { H31 } & \text { December effect }\end{array}$

\section{Introduction}

The disposition effect, disproportionately closing winning positions and holding losing ones, is a robust stylized fact concerning individual investor behavior (Barberis \& Xiong (2009)). Different explanations for this behavior have been offered. These include: prospect theory preferences, mental accounting, regret avoidance, lack of self-control, re-balancing needs, higher transaction costs at lower prices, liquidity demands, (erroneous) private beliefs that indicate holdings are over or under-valued, and a mechanical effect from predominantly rising markets.

With so many competing rationalizations it is unsurprising that disposition effect tests are "severely confounded by various possible factors affecting trading" (Ben-David \& Hirshleifer (2012)). Notable among these factors is tax optimization, where individual investors' desire to minimize their tax liability can lead to byzantine trading strategies. A particular combination of tax regime and personal finances could motivate a householder to variously 
(i) realize losses while they are short-term (ii) take profits only if they are long-term (iii) postpone taxable gains by continuing to hold unattractive investments (iii) indulge in taxswaps ${ }^{1}$ and/or (iv) offset gains with forced losses, especially towards the end of the fiscal year.

Generally, the disposition bias (sell winners, keep losers) operates in the opposite direction of tax optimization (keep winners, sell losers), but this is not necessarily always true. Much of the empirical research suggests that (at least, under U.S. tax codes) December is when most of the tax-motivated selling occurs although tax considerations may have a year-round impact. Relatively little research has considered the disposition effect in the absence of taxes. An exception is Dhar \& Zhu (2006) who note that taxable and tax-deferred accounts exhibit similar disposition outcomes.

Researchers rarely are able to avoid confounding tax effects because empirical studies have typically been in settings with investment taxes. In contrast, the analysis here provides a number of interesting results that are obtained free from tax distortions.

\section{Data set}

\subsection{Overview}

I analyze investments of individual households using disaggregated daily portfolio data. The householders were users of an investment platform which provides online access to over 400 mutual funds, of a wide range of assets classes and geographies, and whose mixture did not change materially over the sample period. Users had $24 \times 7$ access to portfolio statements and transaction capabilities; trades were executed each business day. The users are Singapore-resident for tax purposes. This means they enjoy the benefits of a retail investorfriendly tax regime: no capital gains tax, no tax on interest nor on dividends. In brief, the accounts studied are tax-free.

The detailed, disaggregated data support household-level and aggregate analyses. I am able to compute daily realized and paper gains/losses for each household, as well as observe individual trades and their (actual or potential) buy and sell prices.

\footnotetext{
${ }^{1}$ Selling a losing instrument and immediately purchasing an instrument with similar risk characteristics, thus maintaining the same expected risk-reward profile.
} 


\subsection{Summary statistics}

The transactional data are from 460,000 trades on mutual funds over the period 2001-2012. The data is of audited and reconciled financial records, that is, of exceptional accuracy. Table 1 shows that the total flow of money associated with these trades is $\mathrm{S} \$ 4.4$ billion (around US $\$ 3.5$ billion at 2013 rates). Table 2 characterizes the associated portfolios of the 4,800 households. Portfolios with a market value of under $\$ 1,000$ are excluded from the analysis, to help reduce any "play money" bias.

Table 1 Summary statistics of main trade types Monetary values in SGD. Total sample of all individuals.

\begin{tabular}{ccccc}
\hline Type & No. & Total flow (\$) & $\begin{array}{c}\text { Mean trades } \\
\text { per investor }\end{array}$ & $\begin{array}{c}\text { Mean amount }(\$) \\
\text { per trade }\end{array}$ \\
\hline buy & 116,890 & $921,522,256$ & 14.81 & 11,552 \\
sell & 55,048 & $610,252,812$ & 6.98 & 10,517 \\
switch-in & 145,325 & $1,329,056,018$ & 18.42 & 6,201 \\
switch-out & 145,356 & $1,294,592,567$ & 18.42 & 5,821 \\
\hline
\end{tabular}

Table 2 Summary statistics of household portfolios

\begin{tabular}{rrrrrrrr}
\hline & Mean & Median & Min & Max & S.D. & Kurtosis & Skewness \\
\hline Portfolio (\$) & & & & & & & \\
Size & 58,139 & 19,094 & 1,000 & & 145,026 & 166.4 & 10.3 \\
Total flow in & 79,248 & 10,000 & 0 & & 217,314 & 93.8 & 7.6 \\
Total flow out & 37,739 & 1,072 & 0 & & 104,157 & 64.2 & 6.4 \\
\hline Demographics & & & & & & & \\
Age & 38.9 & 37.7 & 19.9 & 83.0 & 9.2 & 0.6 & 0.8 \\
\hline Share & & & & & & & \\
Risky (a) & 0.927 & 1.000 & 0.000 & 1.000 & 0.196 & 12.3 & -3.5 \\
Equity & 0.847 & 1.000 & 0.000 & 1.000 & 0.277 & 2.9 & -2.0 \\
Bond & 0.120 & 0.000 & 0.000 & 1.000 & 0.246 & 5.2 & 2.4 \\
Pension & 0.575 & 0.775 & 0.000 & 1.000 & 0.447 & -1.7 & -0.3 \\
\hline No. months with a... & & & & & & \\
switch & 3.70 & 0.00 & 0 & 105 & 8.90 & 23.8 & 4.3 \\
sell & 2.54 & 1.00 & 0 & 72 & 5.02 & 30.0 & 4.4 \\
buy & 8.45 & 2.00 & 0 & 132 & 17.50 & 14.3 & 3.5 \\
\hline Tenure & 51.3 & 46.0 & 1 & 135 & 37.6 & -0.9 & 0.4 \\
Start month & 57.0 & 55.0 & 1 & 135 & 33.6 & -0.6 & 0.3 \\
Last month & 107.3 & 135.0 & 2 & 135 & 37.3 & -0.6 & -1.0 \\
\hline
\end{tabular}

Monetary values in SGD. 4,803 households. Period Oct-2001 (Month 1) to Dec-2012 (Month 135)

\section{Econometric methodology}

The hypothesis tested is that, in aggregate, households tend to sell their winners and hold their losers. I compute the proportion of gains realized (PGR) and proportion of losses realized (PLR) as per Odean (1998). The null hypothesis is that PGR $\leq$ PLR. 


$$
\begin{aligned}
\text { PGR } & =\frac{\text { Realized Gains }}{\text { Realized Gains }+ \text { Paper Gains }} \\
\text { PLR } & =\frac{\text { Realized Losses }}{\text { Realized Losses + Paper Losses }}
\end{aligned}
$$

The standard error to calculate the t-statistic for the difference in the proportions PGR and PLR, also from Odean (1998), is

$$
\text { se }=\sqrt{\frac{\operatorname{PGR}(1-\mathrm{PGR})}{n_{r g}+n_{p g}}+\frac{\operatorname{PLR}(1-\mathrm{PLR})}{n_{r l}+n_{p l}}}
$$

where $n_{r g}, n_{p g}, n_{r l}$, and $n_{p l}$ are the number of realized gains, paper gains, realized losses, and paper losses.

This is a joint test of the hypothesis of selling outcomes and of the specification of the reference point from which gains/losses are determined. For reference point I use the average purchase price of the fund; users of the platform are shown a profit and loss figure that derives from this same reference point. Hence, it is highly plausible that sell decisions are influenced by this particular specification.

\section{Results}

\subsection{Aggregate analysis}

Table 3 shows the results of the test of the null hypothesis. The t-statistics range from 24 to 89 which strongly suggests ${ }^{2}$ that the households under study, in aggregate, have a tendency to hold losers and sell winners - even when taxes play no part in their decision making.

The effect of tax distortions across the fiscal year may be examined by conditioning on time. Odean (1998) computes the ratio of PGR to PLR for each month and finds a downward slope due to tax-loss selling, as illustrated by the dashed lines in Figure 1. As in the U.S. the tax year in Singapore is 1 January to 31 December.

The same ratio is plotted for the householders under study and shown as solid lines in Figure 1. Investors in both studies have a mean PGR/PLR of around 1.5, that is, on average, retail investors tend to sell $50 \%$ more of their winners than they do their losers.

Although the plots derive from completely different data sets, and we cannot know in retrospect what the behavior of Odean's traders in a zero tax regime might have been, a

\footnotetext{
${ }^{2}$ Odean cautions that the independence assumption will not hold perfectly, and that this could inflate test statistics.
} 
number of conclusions may be cautiously drawn. There is no December effect when taxes are absent, and moreover, it seems the "tax-free disposition effect" has no obvious seasonality.

The stylized results I present in chart 1.B illustrate how the presence of taxes appears to lead to a rotation of the line of PGR/PLR ratio: householders sell losers in increasing proportions as the year unfolds.

Table 3 Results of test for disposition effect

\begin{tabular}{cccccccccc}
\hline & All & Jan-Nov & Jan & Mar & May & Jul & Sep & Nov & Dec \\
\hline PLR & 0.110 & 0.111 & 0.107 & 0.102 & 0.113 & 0.112 & 0.113 & 0.108 & 0.106 \\
PGR & 0.165 & 0.166 & 0.159 & 0.177 & 0.175 & 0.160 & 0.171 & 0.158 & 0.160 \\
Difference & -0.0550 & -0.0551 & -0.0520 & -0.0752 & -0.0629 & -0.0484 & -0.0577 & -0.0501 & -0.0543 \\
t-statistic & -89.1 & -85.7 & -24.8 & -34.6 & -28.6 & -23.1 & -27.4 & -24.1 & -24.6 \\
\hline No. RG & 118,159 & 108,675 & 9,631 & 9,617 & 10,373 & 9,650 & 10,371 & 9,929 & 9,491 \\
No. PG & 596,984 & 547,132 & 50,937 & 44,705 & 48,739 & 50,659 & 50,258 & 52,996 & 49,853 \\
No. RL & 57,740 & 53,954 & 4,632 & 4,550 & 4,676 & 5,163 & 5,485 & 4,670 & 3,810 \\
No. PL & 465,847 & 433,601 & 38,663 & 40,115 & 36,871 & 41,092 & 42,879 & 38,692 & 32,255 \\
\hline PGR/PLR & 1.50 & 1.50 & 1.49 & 1.74 & 1.56 & 1.43 & 1.51 & 1.47 & 1.51 \\
\hline
\end{tabular}

This table compares the aggregate PGR to the aggregate PLR, as defined in equation (1), and computes tstatistics from equation (2). Component measures are aggregated over time (2001-2012), and across all accounts and households in the sample. Monthly figures were computed for all twelve months but for space reasons only a selection is shown.
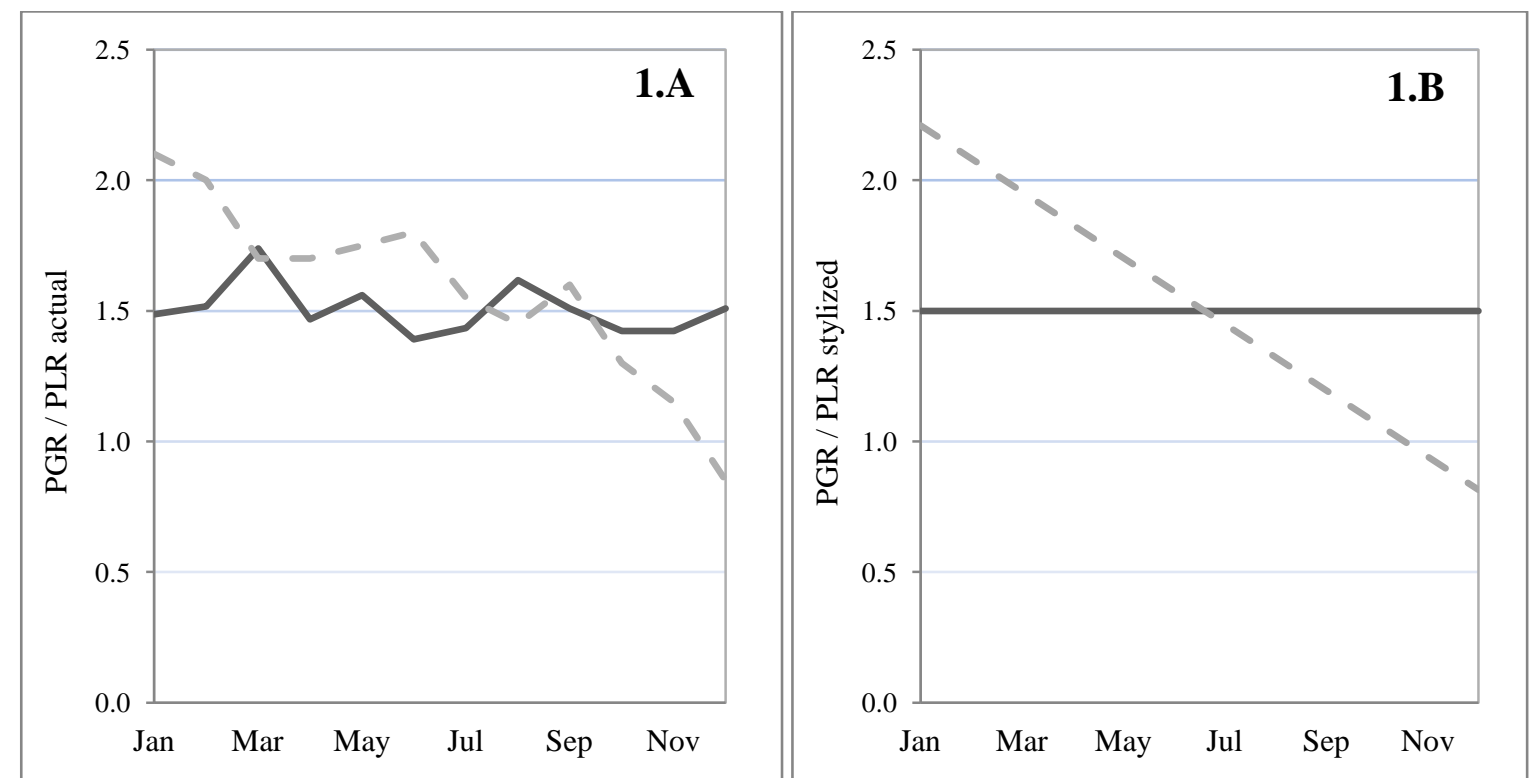

Figure 1 Ratio of PGR to PLR for each month. Aggregated over time (2001-2012) and across all accounts. Left chart 1.A shows actual values, right chart 1.B shows stylized results. The dashed line in chart 1.A is from Figure 2 in Odean (1998). The setting for the dashed lines is with taxes, and the solid line in a setting without taxes. 


\subsection{Disaggregated analysis}

It is of interest to determine whether the observed disposition behavior is rational (under standard utility assumptions) or economically beneficial. Thus I examine the link between PLR-PGR and risk-adjusted investment performance, measured at the household level. Performance is estimated by realized Sharpe ratio and realized Jensen's alpha, the intercept from a multi-factor regression ${ }^{3}$. I sort on PLR-PGR and group into quintiles.

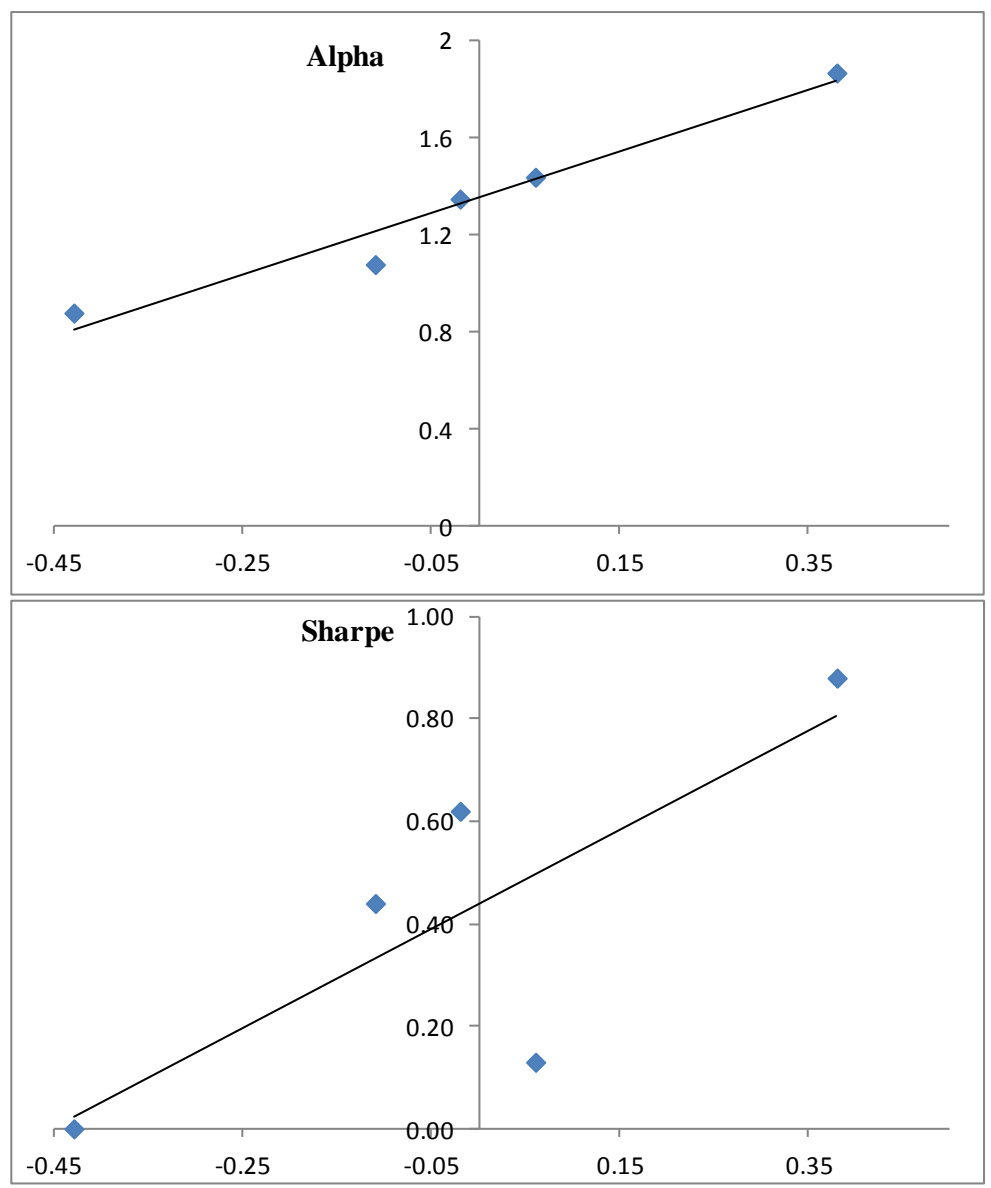

Figure 2 The tendency to sell winners is counter-productive. Plots of quintile mean $A L P H A$ and SHARPE against the corresponding quintile mean of PLR-PGR, see Table 4. The values of SHARPE are normalized to zero for the worst performance. The line fits are illustrative.

The results are shown in Table 4 and visualized in Figure 2; the greater their disposition effect the worse is householders' investment performance. Although we cannot be sure disposition bias is a cause of under-performance, the correlation is striking.

\footnotetext{
${ }^{3}$ The factors were the MSCI Singapore (S\$) MSSINGL S\$ for the equity index and the Singapore govt bond total return (S\$) Y07604 for the bond index (both sources Datastream). The Singapore Govt Dealers 3M T-Bill Yield (S\$) SGSTBILL3M is used for the risk free rate (source: sgs.gov.sg).
} 
Table 4 Sort of performance by disposition bias

\begin{tabular}{|c|c|c|c|c|c|c|c|c|}
\hline & \multicolumn{5}{|c|}{ Quintile } & \multirow[b]{2}{*}{$\begin{array}{l}\text { HIGH- } \\
\text { LOW }\end{array}$} & \multirow[b]{2}{*}{ tstat } & \multirow[b]{2}{*}{ pvalue } \\
\hline & LOW & Q2 & Q3 & Q4 & $\mathrm{HIGH}$ & & & \\
\hline Alpha $(\%)$ & 0.88 & 1.08 & 1.35 & 1.44 & 1.87 & 0.99 & 2.42 & $0.016 * *$ \\
\hline Sharpe & -6.66 & -6.22 & -6.04 & -6.53 & -5.78 & 0.88 & 1.60 & 0.111 \\
\hline PLR-PGR & -0.43 & -0.11 & -0.02 & 0.06 & 0.38 & & & \\
\hline
\end{tabular}

Investment outcomes as measured by Jensen's Alpha and by Sharpe ratio, sorted by disposition effect measure.

Row PLR-PGR is the quintile mean of the individually computed PLR-PGRs for the households in that quintile.

Sample of 1,679 households. Sharpe ratio x100. Robust t-statistics, **significant at $5 \%$.

\section{Conclusion}

Households in this study show a clear tendency to sell winning funds and hold losers. While this result is not new, it is obtained in the absence of investment taxes, which provides evidence that tax-optimization is not the sole cause of disposition bias. There is no obvious seasonality, such as the December effect, when tax benefits are absent. Additionally, there is evidence that disposition bias correlates positively with inferior risk-adjusted investment performance. Under standard utility assumptions this behavior appears irrational: investment losses are clearly not offset or justified by tax gains, because none exists in this setting. Another possibility is that investors have prospect-theory like preferences.

\section{References}

Barberis, N., \& Xiong, W. (2009). What Drives the Disposition Effect? An Analysis of a Long-Standing Preference-Based Explanation. The Journal of Finance, 64(2), 751-784.

Ben-David, I., \& Hirshleifer, D. (2012). Are Investors Really Reluctant to Realize Their Losses? Trading Responses to Past Returns and the Disposition Effect. Rev Financ Stud, 25(8), 2485-2532.

Dhar, R., \& Zhu, N. (2006). Up Close and Personal: Investor Sophistication and the Disposition Effect. Management Science, 52(5), 726-740.

Odean, T. (1998). Are Investors Reluctant to Realize Their Losses? The Journal of Finance, 53(5), 17751798. 